\title{
Housing-Market Heterogeneity in a Monetary Union
}

February 2013

\begin{abstract}
This paper studies the implications of cross-country housing-market heterogeneity in a monetary union for both shock transmission and welfare. I develop a two-country new Keynesian general equilibrium model with housing and collateral constraints to explore this issue. The conventional wisdom is that welfare would be higher in a monetary union if mortgage markets were homogeneous. This paper shows instead that welfare is higher only when homogenization does not result in higher aggregate volatility (because of financial accelerator effects) or does not redistribute too much wealth from borrowers to savers.
\end{abstract}

Keywords: Housing market, collateral constraint, monetary policy, monetary union JEL Codes: E32, E44, F36 
"Several of the benefits of the euro are already clearly visible, such as the deepening of trade and financial links between euro area countries and the greater resilience of the euro area to external shocks. Today I will discuss both of these accomplishments, and I will also touch on some of the challenges that we continue to face. For instance, there is presently a degree of diversity among euro area countries". Jean-Claude Trichet, October 8, 2007.

\section{Introduction}

Costs and benefits of monetary unions are a much-discussed topic, especially in relation to Europe's Economic and Monetary Union (EMU). There are clear arguments in favor of such unions. A single currency eliminates exchange rate risk, allows rapid price comparison, lowers transaction costs across countries and favors trade. However, costs can arise if countries are not sufficiently similar in some respects. Different national characteristics such as heterogeneous institutions, consumption patterns or financial structures can be a source of different transmission of common shocks. Also, country-specific shocks derived from member heterogeneity can enhance the possible divergence.

In this paper, I focus on housing markets. I develop a two-country new Keynesian general equilibrium model with housing and collateral constraints and I consider how heterogeneous housing markets across members in a currency area affect the transmission of shocks. Then, I compare the dynamics with existing empirical studies and use the model to evaluate from a normative perspective whether housing-market homogenization would be beneficial.

Countries in Europe clearly differ in their housing markets. There is evidence of different loanto-value ratios (LTVs), different proportions of residential debt relative to GDP across countries, and heterogeneous mortgage contracts. Also, house-price movements do not follow the same pattern in every country. The conventional wisdom is that welfare would be higher in a monetary union if mortgage markets were homogeneous. For instance, Maclennan et al. (1998) concluded that an effort should be made toward institutional homogenization among European countries to alleviate possible tensions. In its study "Housing Finance in the Euro Area," the European Central Bank (ECB 2009) also remarks on the importance of such differences for the EMU.

Table 1 in the Appendix shows that countries in Europe have different LTVs, as well as different residential-debt-to-GDP ratios. LTVs are as low as 50\% in Italy and as high as $90 \%$ in the Netherlands, where the debt-to-GDP ratio exceeds 100\%. In countries with a high LTV or a high proportion of 
indebted consumers, housing collateral effects are stronger. Therefore, shocks that affect the value of the collateral constraint could potentially have amplified effects on aggregate variables. This is a clear example of the financial accelerator mechanism, first modeled by Bernanke et al (1999).

Differences in mortgage contracts across countries are another important source of heterogeneity in Europe. In countries such as Germany or France, the majority of mortgages are fixed rate. Conversely, the predominant type of mortgages in such countries as the United Kingdom, Spain, and Greece is variable rate. Calza et al (2009) and Rubio (2011) showed that the mortgage structure of an economy is an important factor in the transmission of shocks.

Extensive studies discuss the differences in the transmission mechanisms between European countries using vector autoregressive (VARs) or large macroeconometric models, but few have focused on the consequences of housing-market heterogeneity from a theoretical standpoint. ${ }^{1}$ A microfounded general equilibrium model is needed to understand the implications of housing-market differences, explore all the interrelations that take place in the economy, and conduct some normative analysis. Closed-economy models do not take into account important interactions, such as the fact that countries trade in both consumption goods and financial assets. A two-country model is also needed to appropriately calibrate the economy, according the corresponding size to each country and thereby comparing the result of the analysis with the evidence.

This paper relates to different strands of the literature. On the one hand, it is related to papers that study the shock transmission under different housing-market characteristics, such as the work by Calza et al (2009). I extend their framework to an international version to address those issues in a monetary union. My paper is also related to two-country models with a financial accelerator, such as that of Gilchrist et al (2002). In contrast to their model, which does not feature a housing market, those by Iacoviello and Smets (2006) and Aspachs and Rabanal (2008) develop a monetary-union model with housing markets and collateral constraints. ${ }^{2}$ I add to this literature by considering the role of mortgagecontract heterogeneity and provide normative analysis. ${ }^{3}$ The present paper also has links with papers that study welfare for different housing-market features. For instance, Campbell and Hercowitz (2009) study the welfare implications of moving to high LTVs. Rubio (2011) analyzes welfare when mortgages can be fixed or variable rate. I also consider these issues, but extend the analysis to a two-country

\footnotetext{
${ }^{1}$ For empirical VAR studies, see Calza et al (2009), Carstensen et al (2009) and Assenmacher-Wesche and Gerlach (2010).

${ }^{2}$ Aspachs and Rabanal (2008) focus on the case of Spain and the EMU.

${ }^{3}$ Darracq and Notarpietro (2008) study optimal monetary policy in a two-country model with housing for the US and the EMU.
} 
setting.

This paper presents a two-country dynamic stochastic general equilibrium (DSGE) model within a monetary union that features a housing market. In each country, there is a group of individuals that are credit constrained and need housing collateral to obtain loans. Countries trade goods, and savers in each country have access to foreign assets. Across countries, I allow for differences in LTVs and in the structure of mortgage contracts (fixed versus variable rate).

In line with empirical studies, my results show that in a monetary union common shocks have a different impact across countries when there is housing-market heterogeneity. In particular, consumption reacts more strongly after a shock when the LTV is high or when mortgages are predominantly variable rate. Since the dynamics of the model seemed plausible, I used it to carry out welfare analysis. From a normative perspective, I found that housing-market homogeneity per se is not necessarily beneficial. Welfare is higher only when homogenization does not result in higher aggregate volatility or does not redistribute too much wealth from borrowers to savers. For example, total welfare is higher in a situation where LTVs are asymmetrical than when they are equal but very high; this is, in line with the findings of Campbell and Hercowitz (2009). Also, for mortgage contracts, homogenization is welfare improving only if it is toward fixed-rate mortgages. These results have clear policy implications.

The paper is organized as follows. Section 2 describes the model. Section 3 presents the model dynamics. Section 4 analyzes welfare. Section 5 is the conclusion. Tables, steady-state relationships, and the linearized model are shown in the Appendix.

\section{Model Setup}

I consider an infinite-horizon, two-country economy inside a monetary union. The home country is denoted by $\mathrm{A}$ and the rest of the union by B. Households consume, work, and demand real estate. There is a financial intermediary in each country that provides mortgages and accepts deposits from consumers. Each country produces one differentiated intermediate good, but households consume goods from both countries. For simplicity, housing is a non-traded good. I assume that labor is immobile across the countries. Firms follow a standard Calvo problem. In this economy, both final and intermediate goods are produced. Prices are sticky in the intermediate-goods sector. Monetary policy is conducted by a single central bank that responds to a weighted average of inflation in both countries. I allow for housing-market heterogeneity across the countries. 


\subsection{The Consumer's Problem}

There are three types of consumers in each country: unconstrained consumers, constrained consumers who borrow at a variable rate, and constrained consumers who borrow at a fixed rate. The proportion of each type of borrower is fixed and exogenous. ${ }^{4}$ Consumers can be constrained or unconstrained in the sense that constrained individuals need to collateralize their debt repayments in order to borrow from the financial intermediary. Interest payments in the next period cannot exceed a proportion of the future value of the current house stock. In this way, the financial intermediary ensures that borrowers are going to be able to fulfill their debt obligations in the next period. As in Iacoviello (2005), I assume that constrained consumers are more impatient than unconstrained ones. ${ }^{5}$ There is a financial intermediary in each country. The financial intermediary in Country A accepts deposits from domestic savers, and it extends both fixed- and variable-rate loans to domestic borrowers.

\subsubsection{The Financial Intermediary}

I assume a competitive framework, and thus the intermediary takes the variable interest rate as given. ${ }^{6}$ The profits of the financial intermediary are defined as: ${ }^{7}$

$$
F_{t}=\alpha_{A} R_{A t-1} b_{t-1}^{c v}+\left(1-\alpha_{A}\right) \bar{R}_{A t-1} b_{t-1}^{c f}-R_{A t-1} b_{t-1}^{u}
$$

In equilibrium, aggregate borrowing and saving must be equal, that is,

$$
\alpha_{A} b_{t}^{c v}+\left(1-\alpha_{A}\right) b_{t}^{c f}=b_{t}^{u}
$$

Substituting (2) into (1), we obtain,

$$
F_{t}=\left(1-\alpha_{A}\right) b_{t-1}^{c f}\left(\bar{R}_{A t-1}-R_{A t-1}\right) .
$$

For the two types of mortgage to be offered, the fixed-interest rate has to be such that the intermediary

\footnotetext{
${ }^{4}$ According to the European Mortgage Federation, the type of mortgage contracts across countries responds to a large extent to institutional or cultural factors, which are out of the scope of the present model. In the short run, the proportion of each type of mortgage contract can fluctuate, but typically it does not imply a change in the fixed- or variable-rate category of the country.

${ }^{5}$ This assumption ensures that the borrowing constraint is binding in the steady state and that the economy is endogenously split into borrowers and savers.

${ }^{6}$ See Andrés and Arce (2008) for a housing model with collateral constraints in which banks are imperfectly competitive and are able to set optimal lending rates.

${ }^{7}$ The superscript $c v$ signifies "constrained variable," $c f$ "constrained fixed".
} 
is indifferent between lending at a variable or fixed rate. Hence, the expected discounted profits that the intermediary obtains by lending new debt in a given period at a fixed-interest rate must be equal to the expected discounted profits the intermediary would obtain by lending it at a variable rate:

$$
E_{\tau} \sum_{i=\tau+1}^{\infty} \beta^{i-\tau} \Lambda_{\tau, i}{\overline{R_{A}}}^{O P T}=E_{\tau} \sum_{i=\tau+1}^{\infty} \beta^{i-\tau} \Lambda_{\tau, i} R_{A i-1}
$$

where $\Lambda_{t, i}=\frac{C_{A t}^{u}}{C_{A t+i}^{u}}$ is the unconstrained-consumer relevant discount factor. Since the financial intermediary is owned by the savers, their stochastic discount factor is applied to the financial intermediary's problem. Notice that, as stated before, variable-rate debt is in one period, but the portion of new debt acquired at a fixed rate is associated with a long-term contract. Since the agent is infinitely lived, I assume here that the maturity of fixed-rate mortgages is also infinity.

We can obtain the equilibrium value of the fixed rate in period $\tau$ from expression (4):

$$
\bar{R}_{A \tau}^{O P T}=\frac{E_{\tau} \sum_{i=\tau+1}^{\infty} \beta^{i-\tau} \Lambda_{\tau, i} R_{A i-1}}{E_{\tau} \sum_{i=\tau+1}^{\infty} \beta^{i-\tau} \Lambda_{\tau, i}} .
$$

Equation (5) states that for every new debt issued at date $\tau$, there is a different fixed-interest rate that has to be equal to a discounted average of future variable-interest rates. Notice that this is not a condition on the stock of debt, but on the new amount obtained in a given period. New debt at a given point in time is associated with a different fixed-interest rate. Both the fixed-interest rate in period $\tau$ and the new amount of debt in period $\tau$ are fixed for all future periods. However, the fixed-interest rate varies with the date the debt was issued, so that in every period there is a new fixed-interest rate associated with new debt in this period. If we consider fixed-rate loans to be long term, the financial intermediary obtains interest payments every period from the whole stock of debt, not only from the new ones. Hence, we can define an aggregate fixed-interest rate as the one the financial intermediary effectively charges every period for the whole stock of mortgages. This aggregate fixed-interest rate is composed of all past fixed-interest rates and past debt, together with the current-period equilibrium fixed-interest rate and new amount of debt. Therefore, the effective fixed-interest rate that the financial intermediary charges for the stock of fixed-rate debt every period is as follows: 


$$
\bar{R}_{A t}=\left\{\begin{array}{c}
\frac{\bar{R}_{A t-1} b_{t-1}^{c f}+\bar{R}_{A t}^{O P T}\left(b_{t}^{c f}-b_{t-1}^{c f}\right)}{b_{t}^{c f}} \text { if } b_{t}^{c f}>b_{t-1}^{c f} \\
\bar{R}_{A t-1} \text { if } b_{t}^{c f} \leq b_{t-1}^{c f}
\end{array}\right\} .
$$

Equation (6) states that the fixed-interest rate that the financial intermediary charges today is an average of what it charged the previous period for the previous stock of mortgages and what it charges in the current period for the new amount. If there is no new debt, the fixed-interest rate will be equal to that of the previous period. Then, in the same way that variable rates are revised every period, fixed-rates are revised by including the new optimal fixed-interest rate for the new debt originating in this period. Importantly, this assumption is not crucial for results. Both $\bar{R}_{A \tau}^{O P T}$ and $\bar{R}_{A t}$ are practically unaffected by interest rate shocks. ${ }^{8}$ This assumption is a way to make the model compatible with the fact that fixed-rate loans are not one-period assets but longer-term ones.

As noted above any profits from financial intermediation are rebated to the unconstrained consumers every period. Even if the financial intermediary is competitive and does not make profits in the absence of shocks, should a shock occur, the fact that only the variable-interest rate is directly affected can generate non-zero profits.

The financial intermediary problem for Country B is symmetrical.

\subsubsection{Unconstrained Consumers (Savers)}

Unconstrained consumers in Country A maximize as follows:

$$
\max E_{0} \sum_{t=0}^{\infty} \beta^{t}\left(\ln C_{t}^{u}+j_{t} \ln H_{t}^{u}-\frac{\left(L_{t}^{u}\right)^{\eta}}{\eta}\right)
$$

Here, $E_{0}$ is the expectation operator, $\beta \in(0,1)$ is the discount factor, and $C_{t}^{u}, H_{t}^{u}$, and $L_{t}^{u}$ are consumption at $t$, the stock of housing, and hours worked, respectively. ${ }^{9} j_{t}$ represents the weight of housing in the utility function. I assume that $\log \left(j_{t}\right)=\log (j)+u_{J t}$, where $u_{J t}$ follows an autoregressive process. A shock to $j_{t}$ represents a shock to the marginal utility of housing. These shocks directly affect housing demand and therefore can be interpreted as a proxy for exogenous disturbances to house prices. $1 /(\eta-1)$ is the aggregate labor-supply elasticity.

Consumption is a bundle of domestically and foreign-produced goods, defined as: $C_{t}^{u}=\left(C_{A t}^{u}\right)^{n}\left(C_{B t}^{u}\right)^{1-n}$,

\footnotetext{
${ }^{8}$ In $\log$-linearized terms, the new fixed interest rate is always equal to the past fixed interest rate, therefore, equation (6) does not introduce a kink.

${ }^{9}$ It is assumed that housing services are proportional to the housing stock.
} 
where $n$ is the size of Country A.

The budget constraint for Country A is as follows:

$$
\begin{gathered}
P_{A t} C_{A t}^{u}+P_{B t} C_{B t}^{u}+Q_{t} H_{t}^{u}+R_{A t-1} B_{t-1}^{u}+R_{t-1} D_{t-1}+\frac{\psi}{2} D_{t}^{2} \leq Q_{t} H_{t-1}^{u}+ \\
W_{t}^{u} L_{t}^{u}+B_{t}^{u}+D_{t}+P_{A t} F_{t}+P_{A t} S_{t}
\end{gathered}
$$

where $P_{A t}$ and $P_{B t}$ are the prices of the goods produced in Countries $\mathrm{A}$ and $\mathrm{B}$, respectively, $Q_{t}$ is the housing price in Country $\mathrm{A}$, and $W_{t}^{u}$ is the wage for unconstrained consumers. $B_{t}^{u}$ represents domestic bonds denominated in the common currency. $R_{A t}$ is the nominal interest rate in Country A. Positive bond holdings signify borrowing, and negative signify savings. However, as we will see, this group will choose not to borrow at all: they are the savers in this economy. $D_{t}$ are foreign-bond holdings by savers in Country A. ${ }^{10} R_{t}$ is the nominal rate of foreign bonds, which are denominated in euros. As is common in the literature, to ensure stationarity of net foreign assets I introduced a small quadratic cost of deviating from zero foreign borrowing, $\frac{\psi}{2} D_{t}^{2} .{ }^{11}$ Savers obtain interest on their savings. $S_{t}$ and $F_{t}$ are lump-sum profits received from the firms and the financial intermediary in Country A, respectively.

Dividing by $P_{A t}$, we can rewrite the budget constraint in terms of goods A:

$$
C_{A t}^{u}+\frac{P_{B t}}{P_{A t}} C_{B t}^{u}+q_{t} H_{t}^{u}+\frac{R_{A t-1} b_{t-1}^{u}}{\pi_{A t}}+\frac{R_{t-1} d_{t-1}}{P_{A t}}+\frac{\psi}{2} d_{t}^{2} \leq q_{t} H_{t-1}^{u}+w_{t}^{u} L_{t}^{u}+b_{t}^{u}+d_{t}+F_{t}+S_{t}
$$

where $\pi_{A t}$ denotes inflation for the goods produced in Country A, defined as $P_{A t} / P_{A t-1}$.

Maximizing (7) subject to (9), we obtain the first-order conditions for the unconstrained group:

$$
\begin{gathered}
\frac{C_{A t}^{u}}{C_{B t}^{u}}=\frac{n P_{B t}}{(1-n) P_{A t}} \\
\frac{1}{C_{A t}^{u}}=\beta E_{t}\left(\frac{R_{A t}}{\pi_{A t+1} C_{A t+1}^{u}}\right), \\
\frac{1-\psi d_{t}}{C_{A t}^{u}}=\beta E_{t}\left(\frac{R_{t}}{\pi_{A t+1} C_{A t+1}^{u}}\right),
\end{gathered}
$$

\footnotetext{
${ }^{10}$ Savers have access to international financial markets.

${ }^{11}$ See Iacoviello and Smets (2006) for a similar specification of the budget constraint.
} 


$$
\begin{gathered}
w_{t}^{u}=\left(L_{t}^{u}\right)^{\eta-1} \frac{C_{A t}^{u}}{n}, \\
\frac{j_{t}}{H_{t}^{u}}=\frac{n}{C_{A t}^{u}} q_{t}-\beta E_{t} \frac{n}{C_{A t+1}^{u}} q_{t+1} .
\end{gathered}
$$

Equation (10) equates the marginal rate of substitution between goods to the relative price. Equation (11) is the Euler equation for consumption. Equation (12) is the first-order condition for net foreign assets. Equation (13) is the labor-supply condition. These equations are standard. Equation (14) is the Euler equation for housing and states that at the margin the benefits from consuming housing have to be equal to the costs.

Combining (11) and (12) we obtain a non-arbitrage condition between home and foreign bonds: ${ }^{12}$

$$
R_{A t}=\frac{R_{t}}{\left(1-\psi d_{t}\right)}
$$

Since all consumption goods are traded and there are no barriers to trade, I assume in this paper that the law of one price holds:

$$
P_{A t}=P_{A t}^{*}
$$

where variables with a star denote foreign variables.

\subsubsection{Constrained Consumers (Borrowers)}

Constrained consumers in Country A are of two types: those who borrow at a variable rate and those who do so at a fixed rate. The difference between them is the interest rate they are charged. The variable-rate constrained consumer faces $R_{A t}$, which will coincide with the rate set by the central bank. The fixed-rate borrower pays $\bar{R}_{A t}$, derived from the financial intermediary's problem. The proportion of variable-rate consumers in Country $\mathrm{A}$ is constant and exogenous and is equal to $\alpha_{A} \in[0,1]$.

Constrained consumers are more impatient than unconstrained ones, that is $\widetilde{\beta}<\beta$. Constrained consumers face a collateral constraint: the expected debt repayment in the next period cannot exceed a proportion of the expectation of tomorrow's value of today's stock of housing:

\footnotetext{
${ }^{12}$ The log-linearized version of this equation could be interpreted as the uncovered interest-rate parity.
} 


$$
\begin{gathered}
E_{t} \frac{R_{A t}}{\pi_{A t+1}} b_{t}^{c v} \leq k_{A} E_{t} q_{t+1} H_{t}^{c v}, \\
E_{t} \frac{\bar{R}_{A t}}{\pi_{A t+1}} b_{t}^{c f} \leq k_{A} E_{t} q_{t+1} H_{t}^{c f},
\end{gathered}
$$

where equations (17) and (18) represent the collateral constraint for the variable- and fixed-rate borrower, respectively. $k_{A}$ can be interpreted as the loan-to-value ratio in Country A. Notice that such models with collateral constraints, the LTV is typically considered exogenous. In reality, the LTV can be a decision variable of the bank, depending on the characteristics of the borrowers. However, this is a macroeconomic model, in which borrowers are a representative agent within their type and therefore the LTV is considered an exogenous parameter. ${ }^{13}$ As I pointed out when I introduced the problem of the financial intermediary, $\bar{R}_{A t}$ is an aggregate interest rate that contains information on all the past fixed-interest rates associated with past debt. Each period, this aggregate interest rate is updated with a new interest rate linked to the new amount of debt originating in that period.

Without loss of generality, I present the problem for the variable-rate borrower since that for the fixed rate is symmetrical. Variable-rate borrowers maximize their lifetime utility function:

$$
\max E_{0} \sum_{t=0}^{\infty} \widetilde{\beta}^{t}\left(\ln C_{t}^{c v}+j_{t} \ln H_{t}^{c v}-\frac{\left(L_{t}^{c v}\right)^{\eta}}{\eta}\right),
$$

where $C_{t}^{c v}=\left(C_{A t}^{c v}\right)^{n}\left(C_{B t}^{c v}\right)^{1-n}$, subject to the budget constraint (in terms of good A):

$$
C_{A t}^{c v}+\frac{P_{B t}}{P_{A t}} C_{B t}^{c v}+q_{t} H_{t}^{c v}+\frac{R_{A t-1} b_{t-1}^{c v}}{\pi_{A t}} \leq q_{t} H_{t-1}^{c v}+w_{t}^{c v} L_{t}^{c v}+b_{t}^{c v}
$$

and subject to the collateral constraint (17). Notice that variable-rate borrowers repay all debt every period and acquire new debt at the current new interest rate. This assumption implies that the interest rate on variable-rate mortgages is revised every period for the whole stock of debt and changed according to the policy rate. ${ }^{14}$ To make the problem for fixed-rate borrowers symmetrical and analogous to existing models with borrowing constraints, I assume the same debt-repayment structure for this type of borrower.

\footnotetext{
${ }^{13}$ At the macroeconomic level, LTVs partly depend on exogenous factors such as regulation. This parameter is usually calibrated to match the average LTV in the country analyzed.

${ }^{14}$ This assumption is consistent with reality, in which variable-interest rates are revised very frequently and changed according to an interest-rate index tied to the interest rate set by the central bank.
} 
Obviously, fixed-rate contracts are not revised every period. However, to make the model more realistic, but still tractable, the fixed-interest rate will be such that a revised fixed rate will be applied only on new debt, keeping constant the interest rate applied to existing debt. In this way, I reconcile the structure of the model with the fact that fixed-rate contracts are long term. ${ }^{15}$

The first-order conditions for these consumers are as follows:

$$
\begin{gathered}
\frac{C_{A t}^{c v}}{C_{B t}^{c v}}=\frac{n P_{B t}}{(1-n) P_{A t}} \\
\frac{n}{C_{A t}^{c v}}=\widetilde{\beta} E_{t}\left(\frac{n R_{A t}}{\pi_{A t+1} C_{A t+1}^{c v}}\right)+\lambda_{A t}^{c v} R_{A t}, \\
w_{t}^{c v}=\left(L_{t}^{c v}\right)^{\eta-1} \frac{C_{A t}^{c v}}{n}, \\
\frac{j_{t}}{H_{t}^{c v}}=\frac{n}{C_{A t}^{c v}} q_{t}-\widetilde{\beta} E_{t} \frac{n}{C_{A t+1}^{c v}} q_{t+1}-\lambda_{t}^{c v} k_{A} E_{t} q_{t+1} \pi_{A t+1} .
\end{gathered}
$$

These first-order conditions differ from those of unconstrained individuals. In the case of constrained consumers, the Lagrange multiplier on the borrowing constraint $\left(\lambda_{t}^{c v}\right)$ appears in equations (22) and (24). As in Iacoviello (2005), the borrowing constraint is always binding, so that constrained individuals borrow the maximum amount they are allowed, and their saving is zero. ${ }^{16}$

The problem for consumers is analogous in Country B.

\section{$2.2 \quad$ Firms}

\subsubsection{Final-Goods Producers}

In Country A, there is a continuum of final-goods producers that aggregate intermediate goods according to the production function:

\footnotetext{
${ }^{15}$ Another option would be to have an overlapping generation model in which we are able to keep track of the debt issued each period. However, the model would become more complex and less comparable with the standard collateral constraint DSGE models, such as that of Iacoviello (2005).

${ }^{16}$ From the Euler equations for consumption of the unconstrained consumers, we know that $R_{A}=1 / \beta$, where variables without a time subscript denote steady-state variables. If we combine this result with the Euler equation for consumption for the constrained individual, we have $\lambda^{c v}=n(\beta-\widetilde{\beta}) / C_{A}^{c v}>0$. Given that $\beta>\widetilde{\beta}$, the borrowing constraint holds with equality in steady state. Since the model is log-linearized around the steady state and low uncertainty is assumed, this result can be generalized to off-steady-state dynamics.
} 


$$
Y_{1 t}^{k}=\left[\int_{0}^{1} Y_{1 t}^{k}(z)^{\frac{\varepsilon-1}{\varepsilon}} d z\right]^{\frac{\varepsilon}{\varepsilon-1}}
$$

where $\varepsilon>1$ is the elasticity of substitution among intermediate goods.

The total demand of intermediate-good $z$ is given by $Y_{A t}(z)=\left(\frac{P_{A t}(z)}{P_{A t}}\right)^{-\varepsilon} Y_{A t}$, and the price index is $P_{A t}=\left[\int_{0}^{1} P_{A t}(z)^{1-\varepsilon} d z\right]^{\frac{1}{\varepsilon-1}}$.

\subsubsection{Intermediate-Goods Producers}

The intermediate-goods market is monopolistically competitive. Following Iacoviello (2005), intermediate goods are produced according to the following production function:

$$
Y_{A t}(z)=\xi_{t}\left(L_{t}^{u}(z)\right)^{\gamma_{A}}\left(L_{t}^{c}(z)\right)^{\left(1-\gamma_{A}\right)}
$$

where $\xi_{t}$ represents technology. I assume that $\log \xi_{t}=\rho_{\xi} \log \xi_{t-1}+u_{\xi t}$, where $\rho_{\xi}$ is the autoregressive coefficient and $u_{\xi t}$ is a normally distributed shock to technology. $\gamma_{A} \in[0,1]$ measures the relative size of each group in terms of labor. $L_{t}^{c}$ is labor supplied by constrained consumers, defined as $\alpha_{A} L_{t}^{c v}+$ $\left(1-\alpha_{A}\right) L_{t}^{c f}$.

The first-order conditions for labor demand are the following: ${ }^{17}$

$$
\begin{gathered}
w_{t}^{u}=\frac{\xi_{t}}{X_{t}} \gamma_{A} \frac{Y_{A t}}{L_{t}^{u}}, \\
w_{t}^{c v}=w_{t}^{c f}=\frac{\xi_{t}}{X_{t}}\left(1-\gamma_{A}\right) \frac{Y_{A t}}{L_{t}^{c}},
\end{gathered}
$$

where $X_{t}$ is the markup, or the inverse of marginal cost.

The price-setting problem for the intermediate-goods producers is a standard Calvo-Yun case. An intermediate-goods producer sells goods at price $P_{A t}(z)$, and $1-\theta$ is the probability of being able to change the sale price in every period. The optimal reset price $P_{A t}^{O P T}(z)$ solves the following:

$$
\sum_{k=0}^{\infty}(\theta \beta)^{k} E_{t}\left\{\Lambda_{t, k}\left[\frac{P_{A t}^{O P T}(z)}{P_{A t+k}}-\frac{\varepsilon /(\varepsilon-1)}{X_{t+k}}\right] Y_{A t+k}^{O P T}(z)\right\}=0 .
$$

The aggregate price level is given as follows:

\footnotetext{
${ }^{17}$ Symmetry across firms allows avoiding index $z$.
} 


$$
P_{A t}=\left[\theta P_{A t-1}^{\varepsilon}+(1-\theta)\left(P_{A t}^{O P T}\right)^{1-\varepsilon}\right]^{1 /(1-\varepsilon)} .
$$

Using (29) and (30) and log-linearizing, we can obtain the standard forward-looking Phillips curve (see equation (74) in the Appendix). ${ }^{18}$

The firm problem is similar in Country B.

\subsection{Aggregate Variables and Market Clearing}

Given $\alpha_{A}$, the fraction of variable-rate borrowers in Country A, we can define aggregates across constrained consumers as the sum of variable-rate and fixed-rate aggregates, so that $C_{t}^{c} \equiv \alpha_{A} C_{t}^{c v}+$ $\left(1-\alpha_{A}\right) C_{t}^{c f}, H_{t}^{c} \equiv \alpha_{A} H_{t}^{c v}+\left(1-\alpha_{A}\right) H_{t}^{c f}$ and $b_{t}^{c} \equiv \alpha_{A} b_{t}^{c v}+\left(1-\alpha_{A}\right) b_{t}^{c f}$.

Therefore, economy-wide aggregates in Country A are $C_{t} \equiv C_{t}^{u}+C_{t}^{c}, L_{t} \equiv L_{t}^{u}+L_{t}^{c}$. The aggregate supply of housing is fixed, so that market clearing requires $H_{t} \equiv H_{t}^{u}+H_{t}^{c}=H{ }^{19}$

The market clearing condition for the final good in Country $\mathrm{A}$ is $n Y_{A t}=n C_{A t}+(1-n) C_{A t}^{*}+$ $n \frac{\psi}{2} d_{t}^{2}$. Domestic financial markets clear: $b_{t}^{c}=b_{t}^{u}$. The world bond market clearing condition is $n d_{t}+$ $(1-n) \frac{P_{B t}}{P_{A t}} d_{t}^{*}=0$, where $d_{t}$ denotes the foreign bonds in real terms. The net foreign asset position follows $d_{t}=\frac{R_{t-1}}{\left(1-\psi d_{t}\right) \pi_{A t}} d_{t-1}+Y_{A t}-C_{A t}-\frac{P_{B t}}{P_{A t}} C_{B t}$. Everything is similar in Country B.

\subsection{Monetary Policy}

The model closes with a Taylor rule, with interest-rate smoothing for interest-rate setting by a single central bank, ${ }^{20}$

$$
R_{t}=\left(R_{t-1}\right)^{\rho}\left(\left[\left(\pi_{A t}\right)^{n}\left(\pi_{B t}\right)^{(1-n)}\right]^{\left(1+\phi_{\pi}\right)}\left[\left(\frac{Y_{A t} / Y_{A t-1}}{Y_{A}}\right)^{n}\left(\frac{Y_{B t} / Y_{B t-1}}{Y_{B}}\right)^{1-n}\right]^{\phi_{y}} R\right)^{1-\rho} \varepsilon_{R, t}
$$

$0 \leq \rho \leq 1$ is the parameter associated with interest-rate inertia. $\left(1+\phi_{\pi}\right)$ measures the sensitivity of interest rates to current inflation. $\epsilon_{R, t}$ is a white noise shock process with zero mean and variance $\sigma_{\epsilon}^{2}$.

\footnotetext{
${ }^{18}$ This Phillips curve is consistent with other two-country models with financial accelerator. See for instance Gilchrist et al (2002) or Iacoviello and Smets (2006).

${ }^{19}$ An endogenous supply of housing could be easily introduced in a two-sector version of this model. However, the qualitative results would not change for the demand side of the model which is the focus of this paper. For two-sector models, see, for example, Iacoviello and Smets (2006) or Iacoviello and Neri (2010).

${ }^{20}$ This rule is consistent with the primary objective of the ECB being price stability. This type of rule is also used in other monetary-union models. See Iacoviello and Smets (2006) or Aspachs and Rabanal (2008).
} 


\section{Dynamics}

\subsection{Evidence}

The effects of monetary policy and other shocks on the main variables in the economy are potentially different, depending on the housing-market characteristics in each country. ${ }^{21}$ For example, the loan-tovalue ratio is a crucial parameter because it implies the degree of credit accessibility for borrowers and therefore the strength of the financial accelerator. When LTVs are high, shocks that affect the value of the collateral are amplified owing to the financial accelerator effect. The prevalent mortgage structure is also relevant for the transmission of shocks. For those consumers with variable-rate mortgages, after a positive interest-rate shock, interest-rate payments increase by more than for the fixed-rate case. Also, the value of their collateral decreases by more.

Several empirical studies analyze the effects of cross-country housing-market differences on the responses of the economy to shocks. Calza et al (2009) conducted a VAR-based analysis of the effects of monetary-policy shocks on other variables. They classified countries according to their degree of development of mortgage markets and, depending on their mortgage structure, fixed- or variable-rate mortgages. They showed that the size of the peak effect of a monetary-policy shock on house prices is positively related both to the flexibility in mortgage markets and the variability of the mortgage rate. They found consumption to be more responsive when the mortgage rate was variable, but differences were not so great for the LTV ratio. Carstensen et al (2009) also implemented a VAR study to analyze the cross-country differences in the response of house prices and other variables to a monetary-policy shock. They likewise found that the house-price response of a monetary-policy shock was correlated with the flexibility of mortgage markets and that countries that exhibited a strong response in house prices also showed a strong reaction in output, consumption, and inflation. Assenmacher-Wesche and Gerlach (2010) estimated a VAR on a panel data set, including consumer prices, real GDP, residential property prices, short-term interest rates, and credit, for a sample of 18 OECD economies. They showed that real GDP and residential-property prices decline more in response to a monetary-policy shock in economies with flexible mortgage markets, although the differences were not so great when they grouped the countries according to their LTVs. When they divided the countries according to their mortgage structure, they found that the effects of monetary policy on GDP were faster when variable-rate mortgages were

\footnotetext{
${ }^{21}$ Erceg and Levin (2006), Barsky et al (2007), Monacelli (2009) and Carlstrom and Fuerst (2010) find that in a model with a construction sector, the housing sector is more sensitive to monetary-policy shocks. In this paper, I consider only the nondurable sector.
} 
prevalent.

In this section, I present the dynamics of the model. By using a plausible calibration, I show that the model delivers impulse responses that are in line with the empirical evidence; therefore, it is suitable for policy and welfare analysis. In particular, to make the results comparable with those of empirical studies, I conducted the following experiments. First, I divided the euro area into two blocks, one with little mortgage debt and the other with high mortgage debt, and showed how these two markets responded to common shocks. The hot housing block is composed of countries with high LTVs (greater than $75 \%$ ), which proxy for high accumulation debt; in the cold block, countries have low LTVs. Second, I divided the area into one group, in which agents borrow at a variable mortgage interest rate, and another, in which they do so at a fixed rate. Parameters were chosen so that they realistically reflected euro-area data. Impulse responses of consumption and house prices to interest rate, technology, and house-price shocks are displayed for all subgroups.

\subsection{Parameter Values}

The discount factor for savers, $\beta$, is set to 0.99 so that the annual interest rate is $4 \%$ in steady state. The discount factor for borrowers, $\widetilde{\beta}$, is set to $0.98 .^{22}$ The steady-state weight of housing in the utility function, $j$, is set to 0.1 in order for the ratio of housing wealth to GDP to be approximately 1.40 in the steady state. ${ }^{23}$ I set $\eta=2$, implying a value of the labor supply elasticity of $1 .^{24}$ For the loan-tovalue ratio, I considered the weighted average for the cold housing block to be 0.62 . For the hot housing block, it was 0.79 , while the total average was 0.68 . The labor-income share of unconstrained consumers, $\gamma_{A}=\gamma_{B}$, was set to $0.7 .{ }^{25}$ I picked a value of 6 for $\varepsilon$, the elasticity of substitution among intermediate goods. This value implies a steady-state markup of 1.2. The probability of not changing prices, $\theta$, is set to 0.75 , implying that prices change every four quarters on average. For the Taylor Rule parameters, I used $\rho=0.8, \phi_{\pi}=0.5$. The first value reflects a realistic degree of interest-rate smoothing. ${ }^{26} \phi_{\pi}$ is consistent with the original parameters proposed by Taylor in 1993. For the baseline model, I considered

\footnotetext{
${ }^{22}$ Lawrance (1991) estimated discount factors for poor consumers at between 0.95 and 0.98 at quarterly frequency.

${ }^{23}$ This value corresponds to the US. I assume here that the ratio is similar across most industrialized countries, given the lack of housing wealth data for European countries. See Aspachs and Rabanal (2008).

${ }^{24}$ Microeconomic estimates usually suggest values in the range of 0 and 0.5 (for males). Domeij and Flodén (2006) showed that in the presence of borrowing constraints this estimate could have a downward bias of $50 \%$.

${ }^{25}$ This value is in the range of the estimates of Iacoviello (2005) and Iacoviello and Neri (2010) for the US, and Campbell and Mankiw (1991) for the US, Canada, France, and Sweden. Table 4 in the Appendix shows robustness checks for welfare considering different values of this parameter.

${ }^{26}$ See McCallum (2001).
} 
$\alpha_{A}=\alpha_{B}=1$, that is, all mortgages are variable rate. ${ }^{27}$ However, I also considered the case of fixed-rate mortgages. Country sizes were set depending on GDP weights on the countries included. ${ }^{28}$

Monetary-policy shocks were represented by a $0.29 \%$ increase in the interest rate on a quarterly basis (as in Iacoviello 2005). A technology shock was a $1 \%$ positive technology with 0.9 persistence. ${ }^{29}$ House price shocks had a 0.95 persistence. ${ }^{30}$ I set the size of the shock to the housing-demand parameter at $24.89 \%$, consistent with Iacoviello (2005). Table 2 in the Appendix presents a summary of the parameter values.

\subsection{Hot and cold housing markets}

In this subsection, I divided the euro area into two blocks, one with high debt accumulation and the other one with low debt. As a proxy of the first type, I considered those countries from the union that have high LTVs, and I weighted the block by the countries' appropriate size in terms of their GDP. The remainder constituted the cold housing block.

[Insert Figure 1 here]

Figure 1 shows the effects of a monetary-policy shock, a technology shock, and a house-price shock in a monetary union on consumption and house prices for both the hot and the cold blocks. The solid line represents the hot block, that is, those countries with higher LTVs. The dotted line represents the cold block.

For monetary-policy shocks, the reasoning is as follows: an increase in the interest rate contracts the economy. Savers substitute intertemporally and prefer to save today to consume tomorrow. For borrowers, there is both a direct and an indirect effect in making their consumption decrease. First, their mortgage payments increase, and therefore they consume less. The second effect comes through the collateral constraint. Since housing prices decrease following the interest-rate increase, the value of their collateral decreases. Impatient agents are able to borrow less and hence consume less. This collateral effect, however, is stronger the higher the LTV parameter. We can see that the effects of this shock on consumption are amplified in the hot block, which means that the financial accelerator is stronger there. The effects for house prices are very similar, though.

\footnotetext{
${ }^{27}$ This value makes the model comparable with the standard models, where fixed-rate mortgages are not considered.

${ }^{28}$ The sizes of the hot housing block and variable-rate group of countries were 0.37 and 0.35 , respectively.

${ }^{29}$ This high persistence value for technology shocks is consistent with what is commonly reported in the literature. Smets and Wouters (2002) estimated a value of 0.822 for this parameter in Europe; Iacoviello and Neri (2010) estimated it as 0.93 for the US.

${ }^{30}$ The persistence of the house price shock is consistent with the estimates in Iacoviello and Neri (2010).
} 
The experiment for a common-technology and house-price shock is analogous. Also in this case total consumption would react more in a country that has a high LTV ratio. After a technology shock, the interest rate would decrease and housing prices in both countries increase. The collateral effect is greater in the hot block, with the higher LTV, and therefore its consumption would increase by more. The same applies to the house-price shocks. With increasing house prices, the value of the collateral goes up more in the hot block and thus consumption increases by more.

The model behaved similarly to the empirical studies mentioned above, where for monetary-policy shocks, the effects are moderately stronger in economies with higher LTV ratios. Just like Calza et al (2009) and Assenmacher-Wesche and Gerlach (2010), I found that the peak effect on house prices of monetary-policy shocks was stronger for the hot block. The peak differences between the two blocks was also comparable to this studies around 0.001, as in Assenmacher-Wesche and Gerlach (2010), while it is 0.002 in Calza et al (2009). Also, in line with the empirical studies I mentioned, I found that the responsiveness of consumption to the same shock was larger for the hot block, although the differences were not very great when grouping the countries by LTVs, about a magnitude of 0.0001 (as in AssenmacherWesche and Gerlach (2010), slightly larger in Calza et al (2009)) . Here, the open-economy effects were present. In a closed-economy experiment, countries are unable to smooth consumption by trading both goods and financial assets with the other country. Here, the country that is hit more strongly by the shock can still borrow from the other country to soften the differences. I found that for house-price shocks, differences for consumption between both blocks were amplified.

\subsection{Fixed-versus variable-mortgage rates}

Another source of heterogeneity in housing markets is the mortgage structure. I divided the euro area into two groups of countries; ones that mainly borrow at a variable rate and others that do so at a fixed rate. In Figure 2, I present the responses of consumption and house prices to an interest-rate shock, a technology shock, and a house-price shock when countries are divided according to their interest-rate variability. The solid line represents those countries with variable-rate mortgages while the dotted line corresponds to the fixed-rate block. Given the same shock, consumption reacted more strongly for the group of countries with variable rates, especially for the technology and house-price shocks. When rates in the economy are variable, the shock pass-through should be faster than when they are fixed. Variable rates are tied to the policy rate, set by the central bank, while fixed rates are linked to longer-term rates. Then, mortgage payments increase by more in the variable-rate country, producing an extra decrease in 
consumption. Also, housing demand decreases by more for the variable-rate country and therefore the collateral effects are stronger.

[Insert Figure 2 here]

These results are also in line with the VAR studies, which show that monetary-policy responses are greater for countries with variable rates. As in the case of the hot and cold block, I found that differences are not so great for monetary-policy shocks, they were in fact almost negligible as compared with the empirical studies which showed differences ranging from 0.001-0.005 for consumption and 0.003-0.005 for house prices. The open-economy and general equilibrium effects were also present here, and variablerate countries were able to smooth consumption by trading with the other block. For the technology shock, I found that initially consumption reacted less for variable rates, but that the effects were more persistent. House prices increased more in the variable-rate case, which is what occurs in empirical models. With regard to the house-price shock, the impact response of consumption was stronger when rates were variable.

\section{Welfare Analysis}

We have seen that the transmission of shocks in a monetary union when there is housing-market heterogeneity across countries and that the model delivers impulse responses, which are in line with the empirical literature. However, a remaining question is whether these countries should homogenize their structures or not. Maclennan et al (1998) argued that countries in a monetary union should make an effort toward institutional homogenization in their housing markets. In this section, I use welfare analysis to study whether this is always the case. Since the model previously presented plausible results, I was able to use it to evaluate welfare. In particular, I studied whether countries converging in their degree of credit accessibility and type of mortgage contracts would be beneficial. Here, I focus on these two aspects because, although I consider them exogenous, they are the ones that are most related to institutional features of the economy. Changes in regulation or recommendations of the central bank could make these parameters change.

To address these questions, I numerically evaluated how cross-country asymmetries affect welfare for a given policy rule and for common-technology shocks. As discussed in Benigno and Woodford (2008), the two approaches that have recently been used for welfare analysis in DSGE models include either 
characterizing the optimal Ramsey policy, or solving the model using a second-order approximation to the structural equations for given policy and then evaluating welfare using this solution. As in Mendicino and Pescatori (2007), I take this latter approach to be able to evaluate the welfare of the three types of agents separately. ${ }^{31}$ The individual welfare for savers and borrowers in Country A is defined, respectively, as follows:

$$
\begin{aligned}
V_{u, t} & \equiv E_{t} \sum_{m=0}^{\infty} \beta^{m}\left(\ln C_{t+m}^{u}+j_{t} \ln H_{t+m}^{u}-\frac{\left(L_{t+m}^{u}\right)^{\eta}}{\eta}\right) \\
V_{c v, t} & \equiv E_{t} \sum_{m=0}^{\infty} \widetilde{\beta}^{m}\left(\ln C_{t+m}^{c v}+j_{t} \ln H_{t+m}^{c v}-\frac{\left(L_{t+m}^{c v}\right)^{\eta}}{\eta}\right) \\
V_{c f, t} & \equiv E_{t} \sum_{m=0}^{\infty} \widetilde{\beta}^{m}\left(\ln C_{t+m}^{c f}+j_{t} \ln H_{t+m}^{c f}-\frac{\left(L_{t+m}^{c f}\right)^{\eta}}{\eta}\right) .
\end{aligned}
$$

Following Mendicino and Pescatori (2007), I define social welfare in Country A as a weighted sum of the individual welfare for the different types of households:

$$
V_{t}=(1-\beta) V_{u, t}+(1-\widetilde{\beta})\left[\alpha_{A} V_{c v, t}+\left(1-\alpha_{A}\right) V_{c f, t}\right]
$$

Borrowers and savers' welfare are weighted by $(1-\widetilde{\beta})$ and $(1-\beta)$, respectively, so that the two groups receive the same level of utility from a constant consumption stream. Everything is symmetrical for Country B.

Total welfare is defined as a weighted sum of the welfare in the two countries:

$$
W_{t}=n V_{t}+(1-n) V_{t}^{*}
$$

I performed two experiments and evaluated the results in terms of welfare. First, I considered how welfare would change if the cold block were to become hot. Second, I reported changes in welfare if variable-rate countries moved to a fixed rate. Welfare changes were presented in terms of units of consumption equivalents. As in Ascari and Ropele (2009), I found the constant fraction of steady-state

\footnotetext{
${ }^{31}$ I used the software Dynare to obtain a solution for the equilibrium implied by a given policy by solving a second-order approximation to the constraints, then evaluating welfare under the policy using this approximate solution, as in SchmittGrohe and Uribe (2004). See Monacelli (2006) for an example of the Ramsey approach in a model with heterogeneous consumers.
} 
consumption that would have to be transferred to the agent if there were a welfare loss under the new parameterization. $^{32}$ Then, a negative value of consumption units represented a welfare increase, that is, how much the agent would pay in units of consumption in order to be better off. A positive value means that welfare was decreasing, that is, by how much an agent should be compensated in units of consumption. Table 3 displays the results. The first column shows how welfare (in consumption equivalent units) would change if the cold block increased its LTV from 0.62 to 0.79 . We see that the cold block would be worse off by increasing its LTV. There is, however, a trade-off between the welfare of borrowers and savers. The welfare of the borrowers decreases when the loan-to-value ratio increases. Conversely, savers' welfare increases. This result is in line with that of Campbell and Hercowitz (2009), who performed a welfare analysis in a DSGE model with borrowers and savers and determined that although high LTV ratios have a direct positive effect on welfare through constraint relaxation, other indirect effects may dominate. Notice that $k$, the LTV ratio, is a parameter that strongly affects the collateral constraint. A small change in this parameter can cause very large changes in borrowing that can be excessive. Higher LTVs lead to higher consumption levels, because borrowing constraints are always binding: the more borrowers are offered, the more they take. But this in turn, as shown in Campbell and Hercowitz (2009), changes relative prices. In particular, higher consumption levels imply higher interest rates. This could lead to a situation of overindebtedness in the sense that high repayments could offset the positive effects on constraint relaxation. Smith (2009) shows that these results do not rely on the specific assumptions of Campbell and Hercowitz (2009); even in the simplest model with borrowers, savers, and collateral constraints, this effect takes place. ${ }^{33}$ For aggregate welfare, it is also the case that welfare decreases with higher LTVs. Figure 3 complements these results and shows how welfare would change if the cold block modified its LTV $(k)$ for a continuous range of this parameter. The dot represents the initial baseline case. The dotted and solid lines correspond to the cold and hot blocks, respectively. We see that when the cold block moves from the initial case to a higher LTV, its welfare decreases and therefore, the consumption units needed for compensation increase; since countries share financial and trade links, the hot block can benefit slightly from this welfare loss. This graph shows that heterogeneity in LTVs is not necessarily welfare worsening. I found that homogenization does not deliver the best outcome if both countries have a high value of $k$, because there is too much wealth,

\footnotetext{
${ }^{32}$ The consumption equivalent measure for the saver, as in Ascari and Ropele $(2009)$ is given by $1-\exp \left[(1-\beta)\left(V_{u, n e w}-\right.\right.$ $\left.V_{u, o l d}\right]$, and analogously for the other agents.

${ }^{33}$ Huggett (1997) also found a similar result, but in this case is the reduction in the precautionary motive for saving, driven by the looser borrowing constraints, what leads to the increase in the interest rate.
} 
which is redistributed from borrowers to savers.

[Insert Figure 3 here]

The second column of Table 3 shows the welfare change if the variable-rate countries became fixed rate. We can observe that in the variable block, although total welfare increases by moving to fixed-rate mortgages, this is at the expense of savers, who are worse off. Borrowers prefer fixed-rate contracts as opposed to savers, who prefer variable rates. Even though under fixed-interest rates the monetary authority is losing a policy tool, this type of contract reduces one of the distortions of the economy, and this enhances welfare for borrowers. Equation (62), the log-linearized collateral constraint in the Appendix, shows how debt repayments in real terms decrease with the value of $\alpha$, and this relaxes the constraint. The difference with the previous case is that reducing $\alpha$ does not have such a strong impact on borrowing as increasing $k$. It helps borrowers to lower debt repayments in real terms but without causing overindebtedness (notice that the steady-state value of borrowing does not depend on $\alpha$, but does depend on $k$ ). However, although fixed rates make the collateral constraint less tight for borrowers, savers have to bear all the risk associated with interest-rate variability. For this parameterization, the welfare improvement for borrowers compensates this risk and also aggregate welfare increases with fixed-rate mortgages. Figure 4 shows the evolution of welfare when variable-rate countries move from the baseline to a higher proportion of fixed-rate mortgages. $\alpha=0$ corresponds to fixed-rate mortgages. Higher values of $\alpha$ imply a higher proportion of variable-rate mortgages. The baseline case corresponds to the dot. The dotted and solid lines denote the variable- and fixed-rate countries, respectively. When variable-rate countries move towards fixed-rate mortgages, their welfare increases (consumption units become more and more negative, meaning that they would be willing to pay in terms of consumption in order to achieve this outcome). In this case, homogenization toward fixed-rate mortgages is welfare improving because aggregate volatility is reduced.

[Insert Figure 4 here]

\section{Concluding Remarks}

This paper explores how cross-country housing-market heterogeneity affects the transmission of shocks and welfare in a monetary union. Since there is clear evidence of such heterogeneity across countries 
in Europe, it is relevant to evaluate to what extent this is important. Some normative conclusions are presented as to whether housing-market homogenization is desirable.

For this purpose, I built a two-country DSGE model that featured a housing market. A group of individuals in each country were credit constrained and needed housing collateral to obtain loans. I considered the countries part of a monetary union. I allowed for countries to be heterogeneous in their LTVs and their mortgage contracts, and I found that in line with empirical VAR studies, shocks were transmitted more strongly, in general, if the country had a high LTV or mainly variable-rate mortgages.

The recommendation that European countries should move toward institutional homogenization, particularly with respect to housing markets, is often heard. I performed welfare analysis to explore under which conditions this was the case. From a normative perspective, I found that housing-market homogenization per se is not necessarily beneficial, only when homogenization did not result in higher aggregate volatility or did not redistribute too much wealth from borrowers to savers. In line with the results of recent studies, homogenization toward high LTVs decreased welfare; indirect effects dominated the direct effect of relaxing the borrowing constraints. As for mortgage contracts, the results suggested that countries with predominantly variable-rate contracts should move toward fixed-rate contracts because they reduce the distorting effects of the collateral constraint without causing excessive borrowing.

This paper could serve as a basis for numerous extensions. One of the features of the kind of models used here is that borrowing constraints are always binding and the same agents are always constrained. An overlapping-generations version of the model could deal with this issue, and it would also allow mortgage contracts to be modeled in a more realistic way. ${ }^{34}$ The introduction of an additional sector, which produces houses or a rental market, would also permit the study of other relevant topics that were not the focus of the present paper. For future research, it would be interesting to determine the optimal monetary policy under different sources of asymmetry or take a step towards estimation.

\footnotetext{
${ }^{34}$ See Guerrieri and Iacoviello (2012) that proposed to solve methods of this kind using a shooting algorithm.
} 


\section{Acknowledgements}

I am truly thankful to Fabio Ghironi, Matteo Iacoviello and Peter Ireland for their invaluable advice. A great part of this project was undertaken during my stays at the Federal Reserve Board and at the Bundesbank. I thank the staff there for their financial support and helpful comments. I am also grateful to the seminar and conference participants and discussants at the Bank of Spain, the University of Valencia, the Symposium of Economic Analysis, the Infiniti Conference, the IREBS Conference on Real Estate, the CEUS Workshop "10 Years of the EMU", the Encuentro de Economia Aplicada, and the ECB workshop on Housing Markets and the Macroeconomy. Special thanks go to Antonio Miralles, Galo Nuño and Rubén Segura-Cayuela and an anonymous referee of the Bank of Spain Working Paper series for very useful comments. All errors are mine. The usual disclaimers apply. 


\section{Appendix}

\section{Steady-state relationships}

Relative prices in the steady state are derived from equations (10), (21) and their counterparts for Country B:

$$
\frac{n}{1-n} \frac{P_{B}}{P_{A}}=\frac{C_{A}^{u}}{C_{B}^{u}}=\frac{C_{A}^{c}}{C_{B}^{c}}=\frac{C_{A}^{u *}}{C_{B}^{u *}}=\frac{C_{A}^{c *}}{C_{B}^{c *}}
$$

Interest rates:

$$
R_{A}=R=R_{B}=\bar{R}=\bar{R}^{*}=1 / \beta
$$

We can find the consumption-to-housing ratio for savers and borrowers in Country A by using the first-order conditions for housing:

$$
\begin{gathered}
\frac{C_{A}^{u}}{q H^{u}}=\frac{n}{j}(1-\beta) \\
\frac{C_{A}^{c}}{q H^{c}}=\frac{n}{j}\left[(1-\widetilde{\beta})-k_{A}(\beta-\widetilde{\beta})\right]=\frac{n}{j} \zeta
\end{gathered}
$$

Similarly, for Country B:

$$
\begin{gathered}
\frac{C_{B}^{u *}}{q^{*} H^{u *}}=\frac{(1-n)}{j^{*}}(1-\beta) \\
\frac{C_{B}^{c *}}{q^{*} H^{c *}}=\frac{(1-n)}{j^{*}}\left[(1-\widetilde{\beta})-k_{B}(\beta-\widetilde{\beta})\right]=\frac{(1-n)}{j^{*}} \zeta^{*}
\end{gathered}
$$

Borrowing in the steady state is as follows:

$$
\begin{gathered}
b^{c}=\beta k_{A} q H^{c} . \\
b^{u}+b^{c}=0
\end{gathered}
$$




$$
b^{c *}=\beta k_{B} q^{*} H^{c *}
$$

$$
b^{u *}+b^{c *}=0
$$

From the firm problem, we have that in the steady state:

$$
\begin{gathered}
w^{u}=\frac{1}{X} \gamma \frac{Y_{A}}{L^{u}}, \\
w^{c}=\frac{1}{X}(1-\gamma) \frac{Y_{A}}{L^{c}}, \\
w^{u *}=\frac{1}{X^{*}} \gamma \frac{Y_{B}}{L^{u *}}, \\
w^{c *}=\frac{1}{X^{*}}(1-\gamma) \frac{Y_{B}}{L^{c *}},
\end{gathered}
$$

where $X=X^{*}=\frac{\varepsilon-1}{\varepsilon}$.

Combining the steady-state budget constraint for unconstrained consumers in Country A with (39) and (45) we obtain:

$$
\frac{C_{A}^{u}}{Y_{A}}=\frac{n(\gamma+X-1)}{X\left(1-j k_{A}\right)}
$$

Similarly, for constrained consumers:

$$
\frac{C_{A}^{c}}{Y_{A}}=\frac{1-\gamma}{X} \frac{\zeta n}{\zeta+j k_{A}(1-\beta)}
$$

The market-clearing conditions for goods produced in Country A imply:

$$
\frac{C_{A}^{*}}{Y_{A}}=\frac{n}{1-n}\left(1-\frac{C_{A}^{u}}{Y_{A}}-\frac{C_{A}^{c}}{Y_{A}}\right)
$$

Using (39) and (49) we can find the housing-to-output ratio for savers in Country A: 


$$
\frac{H^{u}}{Y_{A}}=\frac{j(\gamma+X-1)}{X q\left(1-j k_{A}\right)(1-\beta)}
$$

Analogously, using (40) and (50) we can find the housing-to-output ratio for constrained consumers in Country A:

$$
\frac{H^{c}}{Y_{A}}=\frac{(1-\gamma) j}{X q} \frac{n}{\zeta+j k_{A}(1-\beta)}
$$

Similarly, for Country B:

$$
\begin{gathered}
\frac{C_{B}^{u *}}{Y_{B}}=\frac{(1-n)\left(\gamma+X^{*}-1\right)}{X^{*}\left(1-j^{*} k_{B}\right)} \\
\frac{C_{B}^{c *}}{Y_{B}}=\frac{1-\gamma}{X^{*}} \frac{\zeta(1-n)}{\zeta^{*}+j^{*} k_{B}(1-\beta)} \\
\frac{H^{u *}}{Y_{B}}=\frac{j^{*}\left(\gamma+X^{*}-1\right)}{X^{*} q^{*}\left(1-j^{*} k_{B}\right)(1-\beta)} \\
\frac{H^{c *}}{Y_{B}}=\frac{(1-\gamma) j^{*}}{X^{*} q^{*}} \frac{(1-n)}{\zeta^{*}+j^{*} k_{B}(1-\beta)}
\end{gathered}
$$

\section{Log-linearized equations}

Variables in deviations from the steady state are expressed in lower-case and with a hat.

Interest rates

$$
\begin{gathered}
\hat{r}_{A t}=\hat{r}_{B t}+E_{t}\left(\hat{e}_{t+1}-\hat{e}_{t}\right)+\psi, \\
\widehat{\bar{r}}_{A t}=\widehat{\bar{r}}_{B t}=0 .
\end{gathered}
$$

\section{Aggregate demand}

$$
\widehat{c}_{A t}^{u}=E_{t} \widehat{c}_{A t+1}^{u}-\left(\widehat{r}_{A t}-E_{t} \widehat{\pi}_{A t+1}\right),
$$




$$
\begin{aligned}
& \widehat{c}_{B t}^{u *}=E_{t} \widehat{c}_{B t+1}^{u *}-\left(\widehat{r}_{B t}-E_{t} \widehat{\pi}_{B t+1}\right), \\
& \hat{c}_{A t}^{c}=\left(\frac{\zeta+j k_{A}(1-\beta)}{\zeta}\right)\left(\hat{y}_{A t}+\widehat{\xi}_{t}-\hat{x}_{t}\right)-\frac{j}{\zeta}\left(\hat{h}_{t}^{c}-\hat{h}_{t-1}^{c}\right) \\
& +\frac{k_{A} j}{\zeta}\left(\beta \hat{b}_{t}^{c}-\hat{b}_{t-1}^{c}\right)-k_{A} j\left(\alpha_{A} \hat{r}_{A t-1}-\hat{\pi}_{A t}\right), \\
& \hat{b}_{t}^{c}=E_{t} \hat{q}_{t+1}+\hat{h}_{t}^{c}-\left(\alpha_{A} \hat{r}_{A t}-E_{t} \hat{\pi}_{A t+1}\right), \\
& \hat{c}_{B t}^{c *}=\left(\frac{\zeta^{*}+j^{*} k_{B}(1-\beta)}{\zeta^{*}}\right)\left(\hat{y}_{B t}+\widehat{\xi}_{t}^{*}-\hat{x}_{t}\right)-\frac{j^{*}}{\zeta^{*}}\left(\hat{h}_{t}^{c *}-\hat{h}_{t-1}^{c *}\right) \\
& +\frac{k_{B} j^{*}}{\zeta^{*}}\left(\beta \hat{b}_{t}^{c *}-\hat{b}_{t-1}^{c *}\right)-k_{B} j^{*}\left(\alpha_{B} \hat{r}_{B t-1}-\hat{\pi}_{B t}\right), \\
& \hat{b}_{t}^{c *}=E_{t} \hat{q}_{t+1}^{*}+\hat{h}_{t}^{c *}-\left(\alpha_{B} \hat{r}_{B t}-E_{t} \hat{\pi}_{B t+1}\right), \\
& \hat{c}_{A t}-\hat{c}_{B t}=\hat{c}_{A t}^{*}-\hat{c}_{B t}^{*}
\end{aligned}
$$

\section{Housing equations}

$$
\begin{gathered}
\widehat{h}_{t}^{u}=\frac{1}{1-\beta}\left(\widehat{c}_{A t}^{u}-\widehat{q}_{t}\right)-\frac{\beta}{1-\beta} E_{t}\left(\widehat{c}_{A t+1}^{u}-\widehat{q}_{t+1}\right), \\
\widehat{h}_{t}^{u *}=\frac{1}{1-\beta}\left(\widehat{c}_{B t}^{u *}-\widehat{q}_{t}^{*}\right)-\frac{\beta}{1-\beta} E_{t}\left(\widehat{c}_{B t+1}^{u *}-\widehat{q}_{t+1}^{*}\right), \\
\hat{h}_{t}^{c}=\frac{1-k_{A} \beta}{\zeta} \hat{c}_{t}^{c}-\frac{1}{\zeta} \hat{q}_{t}-\frac{k_{A} \beta}{\zeta}\left(\alpha_{A} \hat{r}_{A t}-E_{t} \hat{\pi}_{A t+1}\right)+\frac{\widetilde{\beta}}{\zeta} E_{t} \hat{q}_{t+1}-\frac{\widetilde{\beta}\left(1-k_{A}\right)}{\zeta} E_{t} \hat{c}_{t+1}^{c} . \\
\hat{h}_{t}^{c *}=\frac{1-k_{B} \beta}{\zeta^{*}} \hat{c}_{t}^{c *}-\frac{1}{\zeta} \hat{q}_{t}^{*}-\frac{k_{B} \beta}{\zeta^{*}}\left(\alpha_{B} \hat{r}_{B t}-E_{t} \hat{\pi}_{B t+1}\right)+\frac{\widetilde{\beta}}{\zeta^{*}} E_{t} \hat{q}_{t+1}^{*}-\frac{\widetilde{\beta}\left(1-k_{B}\right)}{\zeta^{*}} E_{t} \hat{c}_{t+1}^{c *} .
\end{gathered}
$$




\section{Aggregate supply}

$$
\begin{gathered}
\hat{y}_{A t}=\frac{\eta+1}{\eta-1} \widehat{\xi}_{t}-\frac{1}{\eta-1}\left(\gamma \hat{c}_{A t}^{u}+(1-\gamma) \hat{c}_{A t}^{c}+\hat{x}_{t}\right), \\
\hat{y}_{A t}=\left(\frac{C_{A}^{u}}{Y_{A}}+\frac{C_{A}^{c}}{Y_{A}}\right) \hat{c}_{A t}+\left(1-\frac{C_{A}^{u}}{Y_{A}}-\frac{C_{A}^{c}}{Y_{A}}\right) \hat{c}_{A t}^{*} \\
\hat{y}_{B t}=\frac{\eta+1}{\eta-1} \widehat{\xi}_{t}^{*}-\frac{1}{\eta-1}\left(\gamma \hat{c}_{B t}^{u *}+(1-\gamma) \hat{c}_{B t}^{c *}+\hat{x}_{t}^{*}\right), \\
\hat{y}_{B t}=\left(\frac{C_{B}^{u *}}{Y_{B}}+\frac{C_{B}^{c *}}{Y_{B}}\right) \hat{c}_{B t}^{*}+\left(1-\frac{C_{B}^{u *}}{Y_{B}}-\frac{C_{B}^{c *}}{Y_{B}}\right) \hat{c}_{B t}, \\
\hat{\pi}_{A t}=\beta \hat{\pi}_{A t+1}-\widetilde{k} \hat{x}_{t}+u_{A t}, \\
\hat{\pi}_{B t}^{*}=\beta \hat{\pi}_{B t+1}^{*}-\tilde{k} \hat{x}_{t}^{*}+u_{B t},
\end{gathered}
$$

where $\widetilde{k}=\frac{(1-\theta)(1-\beta \theta)}{\theta}$ and $u_{A t}$ and $u_{B t}$ are cost-push shocks.

\section{Monetary policy}

$$
\begin{aligned}
& \hat{r}_{A t}=\rho_{A} \hat{r}_{A t-1+}\left(1-\rho_{A}\right)\left[\left(1+\phi_{A \pi}\right) \hat{\pi}_{A t}+\phi_{A y} \hat{y}_{A t}\right]+\widehat{\epsilon}_{A R, t}, \\
& \hat{r}_{B t}=\rho_{B} \hat{r}_{B t-1+}\left(1-\rho_{B}\right)\left[\left(1+\phi_{B \pi}\right) \hat{\pi}_{B t}^{*}+\phi_{B y} \hat{y}_{B t}\right]+\widehat{\epsilon}_{B R, t},
\end{aligned}
$$

Note that under the monetary union regime (76) and (77) become:

$$
\hat{r}_{t}=\rho \hat{r}_{t-1+}(1-\rho)\left\{\left(1+\phi_{\pi}\right)\left[n \hat{\pi}_{A t}+(1-n) \hat{\pi}_{B t}\right]+\phi_{y}\left[n_{A t} \hat{y}_{A t}+(1-n) \hat{y}_{B t}\right]\right\}+\widehat{\epsilon}_{R, t}
$$




\section{References}

[1] Andrés, J., Arce, O., (2008), Banking Competition, Housing Prices and Macroeconomic Stability, Bank of Spain Working Paper, 0830

[2] Ascari, G., Ropele, T., (2009), Disinflation in a DSGE Perspective: Sacrifice Ratio or Welfare Gain Ratio?, Kiel Institute for the World Economy Working Paper, 1499

[3] Aspachs, O., Rabanal, P., (2008), The Effects of Housing Prices and Monetary Policy in a Currency Union, mimeo

[4] Assenmacher-Wesche, K., Gerlach, S., (2010), Financial Structure and the Impact of Monetary Policy on Property Prices, mimeo

[5] Barsky, R., House, C., Kimball, M., (2007), "Sticky-Price Models and Durable Goods", American Economic Review 97, 984-998

[6] Benigno, P., Woodford, M., (2008), Linear-Quadratic Approximation of Optimal Policy Problems, mimeo

[7] Bernanke, B., Gertler, M., Gilchrist, S., (1999), "The Financial Accelerator in a Quantitative Business Cycle Framework," in John B. Taylor and Michael Woodford, eds., Handbook of Macroeconomics

[8] Calza, A., Monacelli, T., Stracca, L., (2009), Housing Finance and Monetary Policy, ECB Working Paper, 1069

[9] Campbell, J., Mankiw, (1991), "The Response of Consumption to Income, a cross-country investigation", European Economic Review, 35, 723-767

[10] Campbell, J., Hercowitz, Z., (2009), "Welfare Implications of the Transition to High Household Debt", Journal of Monetary Economics, 56 (1), 1-16

[11] Carlstrom, C., Fuerst, T., (2010), "Nominal Rigidities, Residential Investment and Adjustment Costs", Macroeconomic Dynamics 14 (01), 136-148

[12] Carstensen, K., Hülsewig O., Wollmershäuser T., (2009), Monetary Policy Transmission and House Prices: European Cross-Country Evidence, CESifo Working Paper No. 2750 
[13] Darracq, M., Notarpietro, A., (2008), Monetary Policy and Housing Prices in an Estimated DSGE Model for the US and the Euro Area, ECB Working Paper 972

[14] Domeij, D., Flodén, M., (2006), "The Labor-Supply Elasticity and Borrowing Constraints: Why Estimates are Biased", Review of Economic Dynamics, 9, 242-262

[15] Erceg, C., Levin, A., (2006), "Optimal Monetary Policy with Durable Consumption Goods", Journal of Monetary Economics 53, 1341-1359

[16] Gilchrist, S., Hairault, J., Kempf, H., (2002), Monetary Policy and the Financial Accelerator in a Monetary Union, ECB Working Paper, 175

[17] Guerrieri, L., Iacoviello, M., (2012), A Toolkit to Solve Models with Occasionally Binding Borrowing Constraints Easily, mimeo

[18] Huggett, M., (1997), "Wealth Distribution in Life-cycle Economies", Journal of Monetary Economics $38,469-494$

[19] Iacoviello, M., (2005), "House Prices, Borrowing Constraints and Monetary Policy in the Business Cycle", American Economic Review, 95 (3), 739-764

[20] Iacoviello, M., Neri, S., (2010), "Housing Market Spillovers: Evidence from an estimated DSGE Model", American Economic Journal: Macroeconomics, American Economic Association, 2 (2), $125-64$

[21] Iacoviello, M., Smets, F., (2006), House Prices and the Transmission Mechanism in the Euro Area: Theory and Evidence from a Monetary Union Model, mimeo

[22] IMF, (2008), World Economic Outlook April 2008, International Monetary Fund

[23] Lawrance, E., (1991), "Poverty and the Rate of Time Preference: Evidence from Panel Data", The Journal of Political Economy, 99 (1), 54-77

[24] Maclennan, D., Muellbauer, J., Stephens, M., (1998), "Asymmetries in Housing and Financial Market Institutions and EMU", Oxford Review of Economic Policy, 4 (3)

[25] McCallum, B., (2001), "Should Monetary Policy Respond Strongly To Output Gaps?," American Economic Review, 91(2), 258-262 
[26] Mendicino, C., Pescatori, A., (2007), Credit Frictions, Housing Prices and Optimal Monetary Policy Rules, mimeo

[27] Monacelli, T., (2006), "Optimal Monetary Policy with Collateralized Household Debt and Borrowing Constraint," in conference proceedings "Monetary Policy and Asset Prices" edited by J. Campbell.

[28] Monacelli, T., (2009), "New Keynesian Models, Durable Goods, and Collateral Constraints", Journal of Monetary Economics 56, 242-254

[29] Rubio, M., (2011), "Fixed- and Variable-Rate Mortgages, Business Cycles, and Monetary Policy", Journal of Money, Credit and Banking, 43 (4), 657-688

[30] Smith A., (2009), Comment on "Welfare Implications of the Transition to High Household Debt" by Campbell J., Hercowitz, Z., Journal of Monetary Economics, 56 (1)

[31] Schmitt-Grohe, S., Uribe, M., (2004), "Solving Dynamic General Equilibrium Models Using a Second-Order Approximation to the Policy Function," Journal of Economic Dynamics and Control, $28,755-775$

[32] Task Force of the Monetary Policy Committee of the European System of Central Banks, (2009), Housing Finance in the Euro Area, ECB Occasional Paper Series, 101 


\section{Figure Legends}

Figure 1: Impulse responses: hot versus cold blocks

Figure 2: Impulse responses: variable- versus fixed-rate countries

Figure 3: Cold countries become hot. Consumption equivalents

Figure 4: Variable-rate countries become fixed-rate. Consumption equivalents

\section{Tables}

\begin{tabular}{lccc}
\hline \hline \multicolumn{1}{c}{ Country } & LTV & Debt/GDP & Rate \\
\hline \hline BELGIUM & 83 & 43,3 & $\mathrm{~F}$ \\
FINLAND & 75 & 58 & $\mathrm{~V}$ \\
FRANCE & 75 & 38 & $\mathrm{~F}$ \\
GERMANY & 70 & 47,6 & $\mathrm{~F}$ \\
ITALY & 50 & 21,7 & $\mathrm{~V}$ \\
IRELAND & 70 & 90,3 & $\mathrm{~F}$ \\
NETHERLANDS & 90 & 105,6 & $\mathrm{~F}$ \\
PORTUGAL & 75 & 67,5 & $\mathrm{~V}$ \\
SPAIN & 70 & 66,4 & $\mathrm{~V}$ \\
\hline \hline
\end{tabular}

Table 1: Characteristics of mortgage markets. Source: IMF (2008) 


\begin{tabular}{|c|c|c|}
\hline \multicolumn{2}{|c|}{ Parameter Values } \\
\hline \hline$\beta$ & .99 & Discount Factor for Savers \\
\hline$\widetilde{\beta}$ & .98 & Discount Factor for Borrowers \\
\hline$j$ & .1 & Weight of Housing in Utility Function \\
\hline$\eta$ & 2 & Parameter associated with labor elasticity \\
\hline$k$ & 0.68 & Average loan-to-value ratio \\
\hline$\gamma$ & .70 & Labor-Income share for borrowers \\
\hline$\alpha$ & 1 & Degree of variability of interest rate \\
\hline$\varepsilon$ & 6 & Elasticity of substitution among intermediate goods \\
\hline$\rho$ & 0.8 & Interest-rate smoothing in Taylor rule \\
\hline$\phi_{\pi}$ & .5 & Inflation Parameter in Taylor rule \\
\hline$\sigma_{\epsilon}$ & 0.29 & Monetary shock standard error \\
\hline$\sigma_{j}$ & 24.85 & House price shock standard error \\
\hline$\rho_{\xi}$ & 0.9 & Technology shock persistence \\
\hline$\rho_{j}$ & 0.95 & House price shock persistence \\
\hline
\end{tabular}

Table 2: Parameter Values

\begin{tabular}{cccc}
\hline \hline \multicolumn{2}{c}{ Cold become Hot } & \multicolumn{2}{c}{ Variable become Fixed } \\
\hline \hline Consumption Units & & Consumption Units \\
\hline \hline Cold Block & 0.006 & Variable Block & -0.70 \\
Savers & -0.01 & Savers & 0.84 \\
Borrowers & 0.29 & Borrowers & -35.5 \\
\hline \hline Hot Block & -0.0004 & Fixed Block & 0.008 \\
Savers & -0.15 & Savers & -0.07 \\
Borrowers & 0.05 & Borrowers & 0.42 \\
\hline \hline Union & 0.003 & Union & -0.25 \\
\hline \hline
\end{tabular}

Table 3: Consumption equivalent measure of welfare when cold countries become hot and variable-rate become fixed-rate (Results represent the constant fraction of steady-state consumption that would have to be transferred to the agent if there were a welfare loss) 


\begin{tabular}{cccccccc}
\hline \hline \multicolumn{3}{c}{ Cold become Hot } & \multicolumn{3}{c}{ Variable become Fixed } \\
\hline \hline & \multicolumn{3}{c}{ Consumption Units } & & \multicolumn{3}{c}{ Consumption Units } \\
\hline \hline & $\gamma=0.6$ & $\gamma=0.7$ & $\gamma=0.8$ & & $\gamma=0.6$ & $\gamma=0.7$ & $\gamma=0.8$ \\
\hline \hline Cold Block & 0.006 & 0.006 & 0.005 & Variable Block & -0.23 & -0.70 & -2.39 \\
\hline \hline Hot Block & -0.001 & -0.0004 & -0.00008 & Fixed Block & 0.007 & 0.008 & 0.004 \\
\hline \hline
\end{tabular}

Table 4 : Robustness analysis for different values of $\gamma$ (Results represent the constant fraction of steady-state consumption that would have to be transferred to the agent if there were a welfare loss) 